\title{
Innovation of New Techniques in Freestyle \& Greco-Roman Wrestling
}

\author{
Kazem Mohseninia Firouzja \\ Department of Research and Development, International Network of Wrestling Researcher Organization, Virginia 22202, US
}

\begin{abstract}
The present research is about learning \& performing term of new innovated techniques and further effects on selected/experienced wrestlers in age level of adolescents and adults at Tehran city with regard to new rules \& regulations in wrestling. Firstly after describing of techniques, all wrestlers reached a suitable body readiness through various physical exercises. Then after complete learning and performing of mental experiences, they could implement the concerned techniques as professional as possible. Since they should be performed in compliance with new rules of wrestling within short terms and with minimum energy consumption, they are really profitable for all wrestlers at professional levels as well.
\end{abstract}

Key words: Performance time, experienced wrestlers, amateur wrestling.

\section{Introduction}

There are two unarmed persons in wrestling who may fight with each other according to the wrestling rules for imbalance and landing the opponent.

There are two Olympic styles throughout the world for wrestling including Greco-Roman \& Freestyle. The only difference between the two styles is different performance. In Greco-Roman style, it is prohibited to use legs of opponent. But it is free to use the legs of opponent in Freestyle one [1]. All matches of both fields are held under the supervision of Wrestling Federation. Greco-Roman style is mostly famous in European countries. A part of considered new techniques is applied in standing position and on upper/lower part of body. The other part is performed in sitting position and on upper/lower part of body. There are specific points for them as 1, 2, 4 and 5 [2].

Wrestling had long terms in the past in which wrestlers used both powerful and risky techniques and even shooting ones [3]. But at present they have no more time for performing the same therefore they are obliged to benefit from any mistakes made by each

Corresponding author: Kazem Mohseninia Firouzja, BSc, assistant professor, research field: new techniques innovation. other as well. As a result, there are special conditions for new techniques as discussed in this research in comparison with the old ones.

Followings are different characteristics of new techniques [4]:

- It is possible to transfer and perform the new techniques by coaches;

- New techniques are easy and understandable for learners;

- Most of wrestlers are able to perform new techniques;

- There are some credits for new techniques;

- We need little time for performing of the mentioned techniques;

- There is not any damage for opponent and no more mistakes;

- It is possible to make maximum pressures on opponent with minimum energy consumption in performing of new techniques.

\section{Research Method}

This research is made on 40 selected wrestlers of Tehran Province at age levels of adolescents and adults. They were selected according to their suitable readiness and no more critical damages. About 20 
persons at age level of adolescents had about 9-12 years of wrestling and the other 20 persons at age level of adults had 15-18 years of experiences at various weights. They had daily 2-3 hours of exercises and also championship level throughout Tehran Province.

Research method is on field basis and due to some changes in wrestling rules, it was made on new innovated techniques [5]. Since the innovated techniques are performed in specific position and condition, there are great differences in credits in this research. Therefore according to the biomechanical position of body and suitable physical conditions, it is possible to obtain better credits with suitable mental imaging [6]. Of course it is easy after complete presentation of researcher and providing best reasoning for sportsmen about training methods.

All new techniques which will be described in next parts are extracted from other techniques and also resulted from innovative mind of researcher as well [7]. Biomechanics science has been considered in performing any one of techniques along with considering movement scope of joints and further reflection and necessary angles of joints and kinesiology [8].

\section{Analysis}

Both approximate and inductive methods were applied for training these methods. Then learners could perform the same by the use of mental imaging and suitable physical situation.

Fig. 1 illustrates all steps of Fitile Yakpa* in freestyle wrestling at age level of adolescents and adults with two grades. As it is obvious, it is applied in sitting position and lower part of body as follows: (1) This technique performing in down; (2) Place yourself between opponent's legs and take his cliff by the other hand; (2) Put your other hand (free hand) on the opponent's knee; (4) Now turn in the mat and perform the technique.

According to the above-mentioned diagram (Fig. 2) from among 20 young wrestlers, only 2 persons could perform the technique correctly. From among 20 adult wrestlers only 5 persons could perform the same as correctly as possible. Both groups had an increasing process within second two weeks because of quick learning. Therefore correct performance of techniques had an increase from 2 persons to 5 at young level and from 5 to 10 persons in adult group. There was an increase in number of person who could perform the considered technique correctly up to 11 persons in young group and also 15 persons in adult group within third two weeks. There was a positive growth rate in young group within last two weeks in a way that 17 persons learned it and performed the same correctly. Two persons who remained in young group could perform it $70 \%$ correctly and the other person could not perform it right due to weak analysis of the movement. Only one person could perform it for $70 \%$ in adult group.

Fig. 3 illustrates both steps of Yekpao Yekdast* in freestyle wrestling at both young and adult levels. It has 4 grades. As it is obvious, this technique is applied at upper part of body as follows: (1) Catch the opponent; (2) Pass your head between his legs; (3) Run toward him and take his hand and perform the technique.

According to Fig. 4, there was not a considerable positive slope in above-mentioned technique Yekpao Yedast* within first two weeks in both young and adult groups. But it was quickly performed within second two weeks at young level because of more reflection and agility. Adult group had lower growth in quick performance of technique within second two weeks due to lack of reflection in performance. Only 5 persons from among 20 adult wrestlers and only 7 persons in young group could perform the concerned technique suitably. The number of wrestlers who could perform it correctly reached to 17 persons in final two weeks. Only three persons from remained persons could perform it correctly $60 \%$ because of weak decision making power and on-time reaction. About 18 persons could perform it correctly at young level within final two weeks and the remained 2 persons could perform 


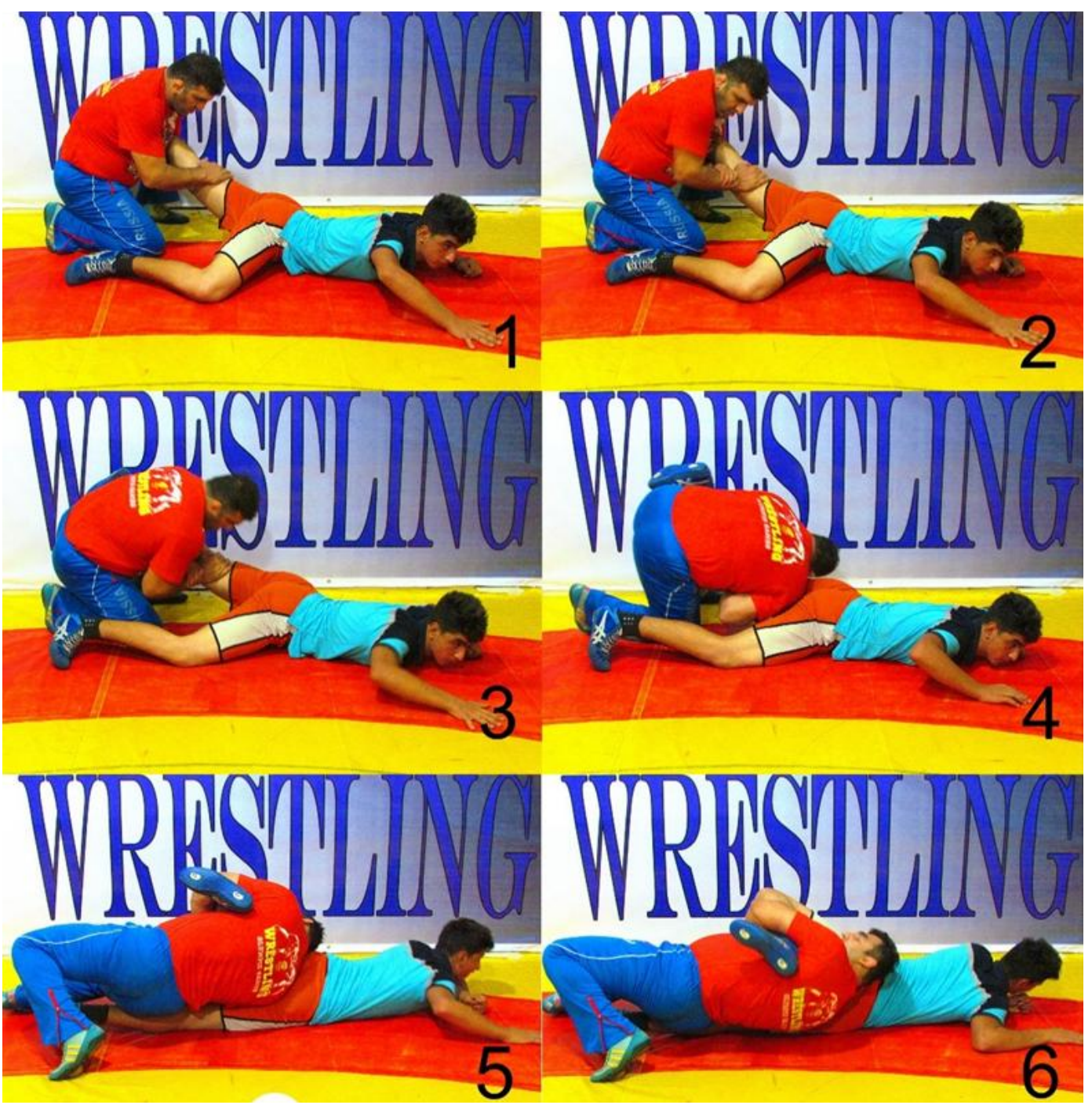

Fig. 1 Fitile Yakpa in freestyle wrestling.

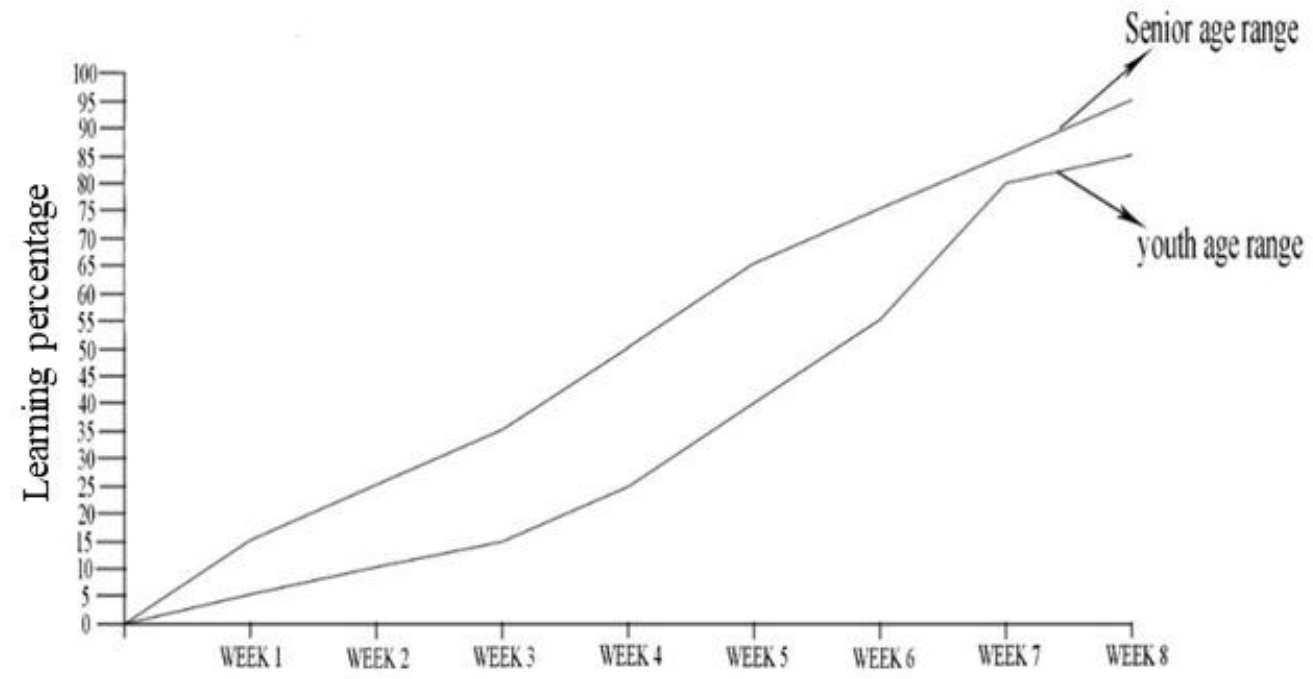

Fig. 2 Fitile Yekpa curve of learning period. 


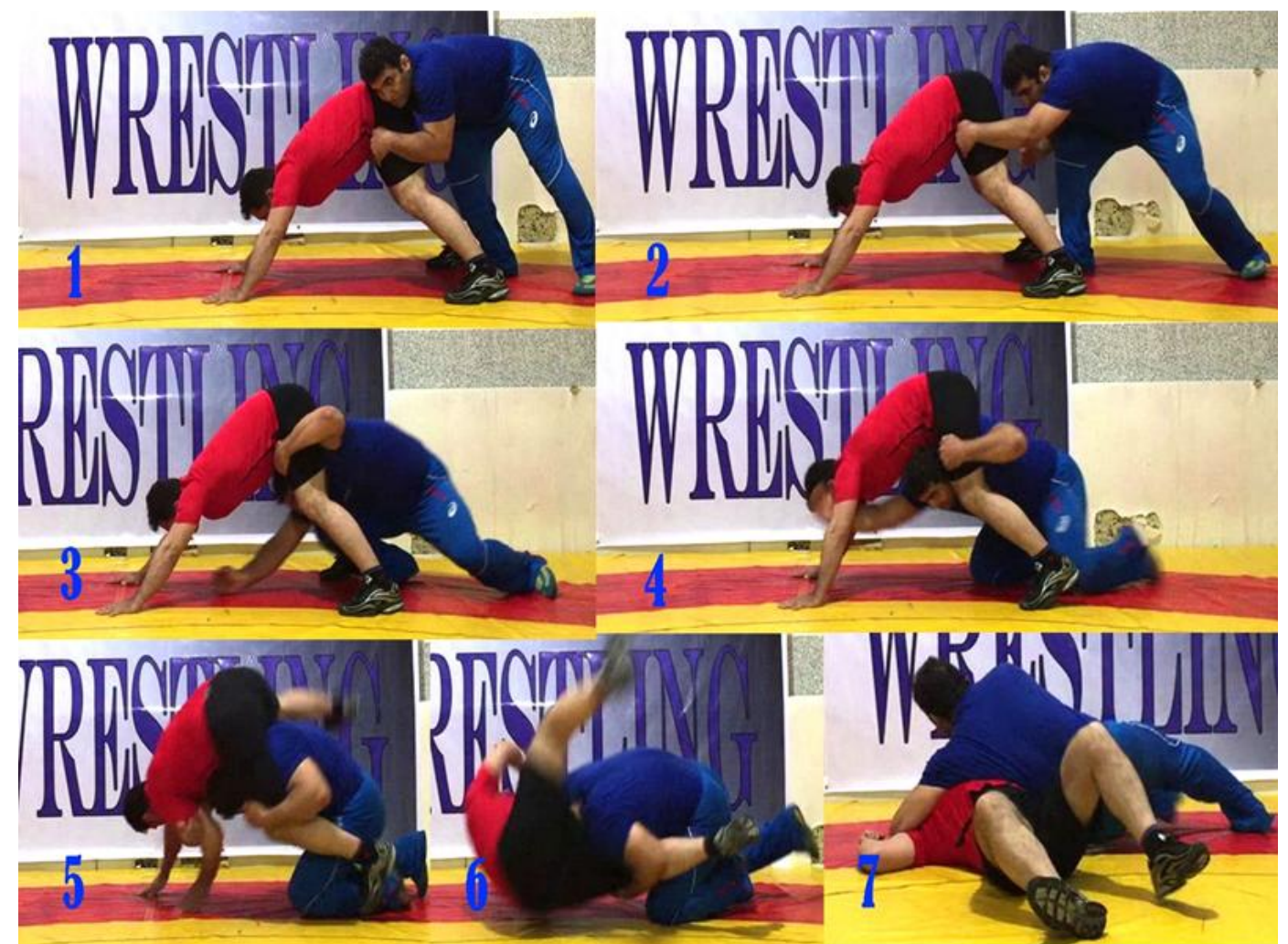

Fig. 3 Yekpao Yekdast* in freestyle wrestling.

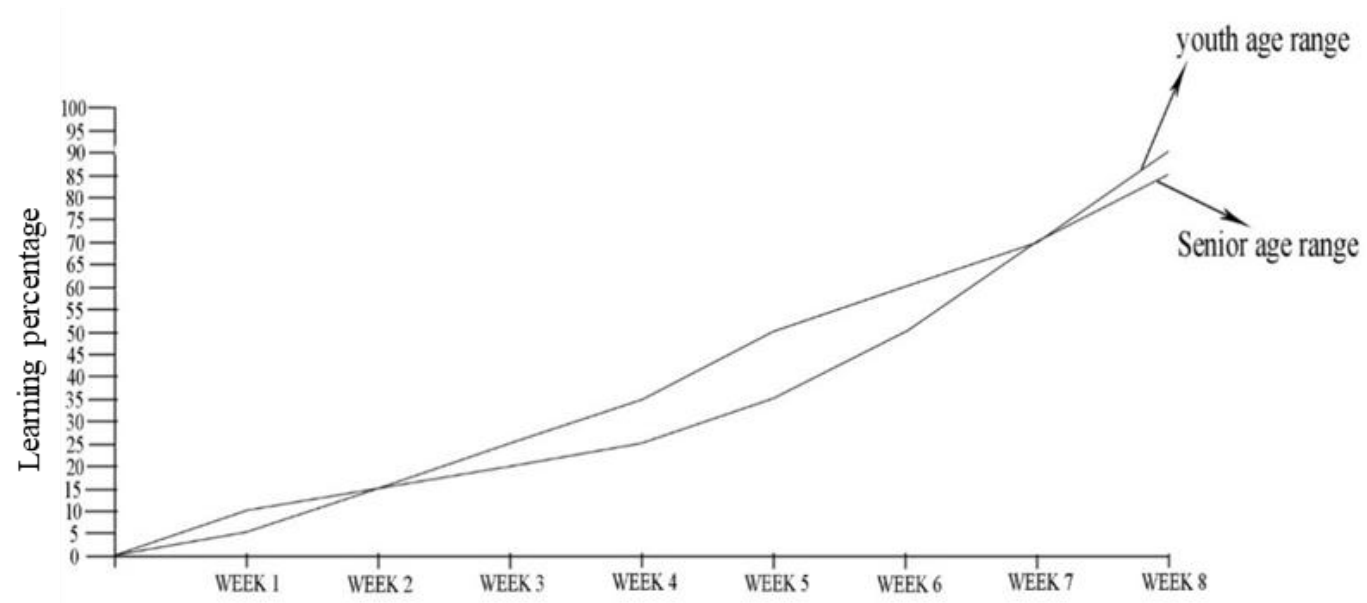

Fig. 4 Yekpao Yekdast curve of learning period.

the same about $70 \%$.

Fig. 5 illustrates three steps of Ghofle Hasirmal* in freestyle wrestling in young and adult groups. At first it has two grades and finally it is possible to knock out the opponent.

As it is obvious, this technique is applied in sitting position and on upper part of body as follows: (1) This technique performing in down; (2) Put one leg between opponent's legs and catch him; (3) Put the guard hand around his waist; (4) Take his opposed hand by the other hand; (5) Take your hand by the hand which is around his waist; (6) Go forward then perform the technique.

As it is obvious in above-mentioned diagram (Fig. 6), only one person from among 20 selected wrestlers could perform this technique correctly and from 


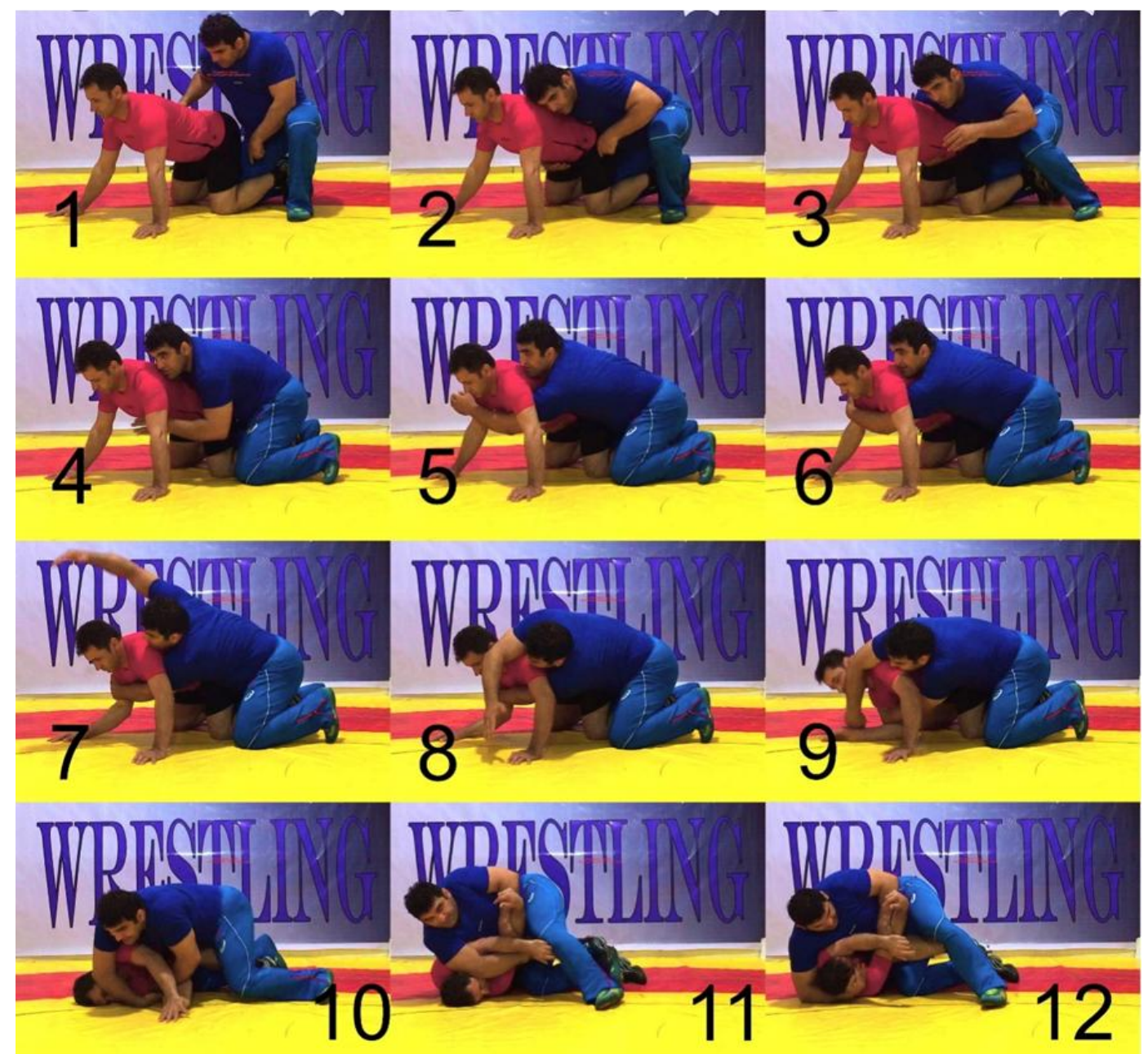

Fig. 5 Ghofle Hasirmal* in freestyle wrestling.

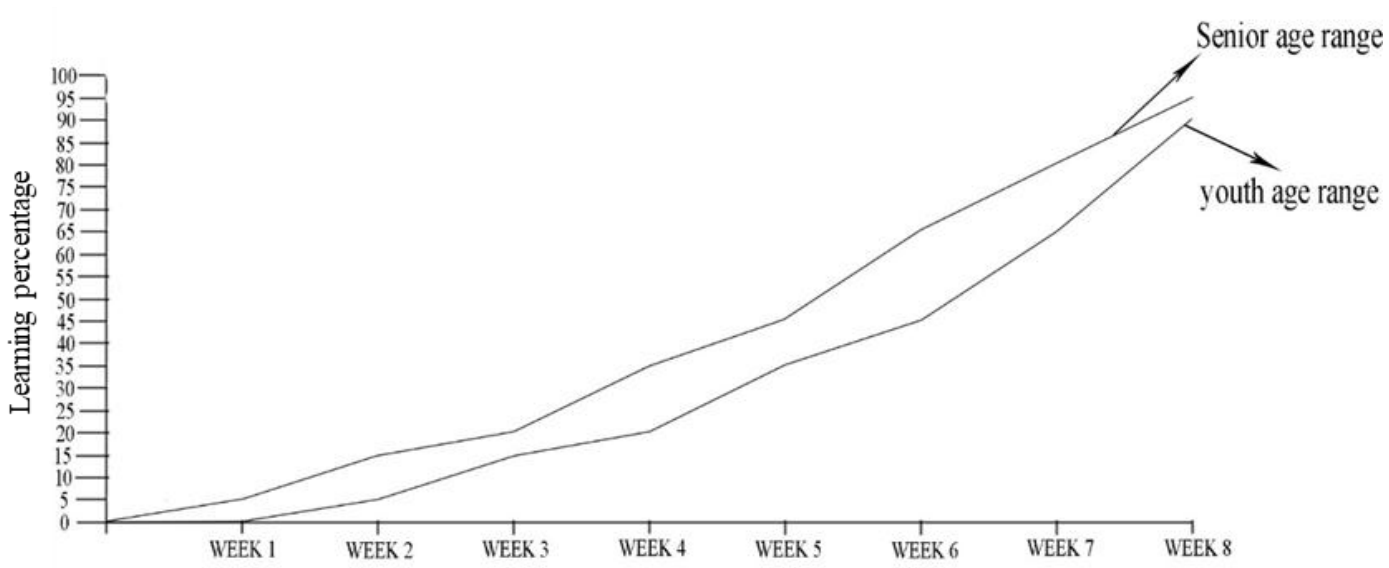

Fig. 6 Ghofle Hasirmal curve of learning period.

20 persons of adult group, only 3 persons could perform the same within first two weeks. In second two weeks 4 wrestlers could perform this technique correctly in young group and only 7 wrestlers could perform the same in adult group. The reason was their experience and presence in various matches for better growth.

There was good growth within third two weeks due 
to better learning of this technique. As a result, about 9 persons of young group performed it correctly. About 13 persons in adult group performed the same correctly as well. The number of young person within last two weeks reached to 18 persons and two persons who remained in young group could perform it $60 \%$ correctly and from remained persons only 4 persons could not perform it correctly due to weak analysis of the movement. Only one person in adult group could perform it correctly within last two weeks due to lack of learning as well.

Fig. 7 illustrates four steps of performing Pashekan* in Freestyle wrestling at both young and adult age levels with two credits. It is applied in sitting position and on upper part of body. As it is obvious, followings are various steps of performing this technique: (1) Catch the opponent; (2) Put your guard leg on the opponent's calf; (3) Put your other leg in the front of guard leg; (4) Sit on the opponent's leg.

There is a weak growth in Pashekan* within first two weeks (Fig. 8). Therefore from 20 selected wrestlers only 2 ones could perform it correctly. About 3 persons in adult group could perform it correctly. There is an increasing growth in both groups within second two weeks because of good learning and finding necessary skills. The number of adults with correct performance of this technique reached from 3 persons to 9 and in young group from 2 up to 6 persons. There was a considerable growth in correct performance of this technique within third two weeks and the number of

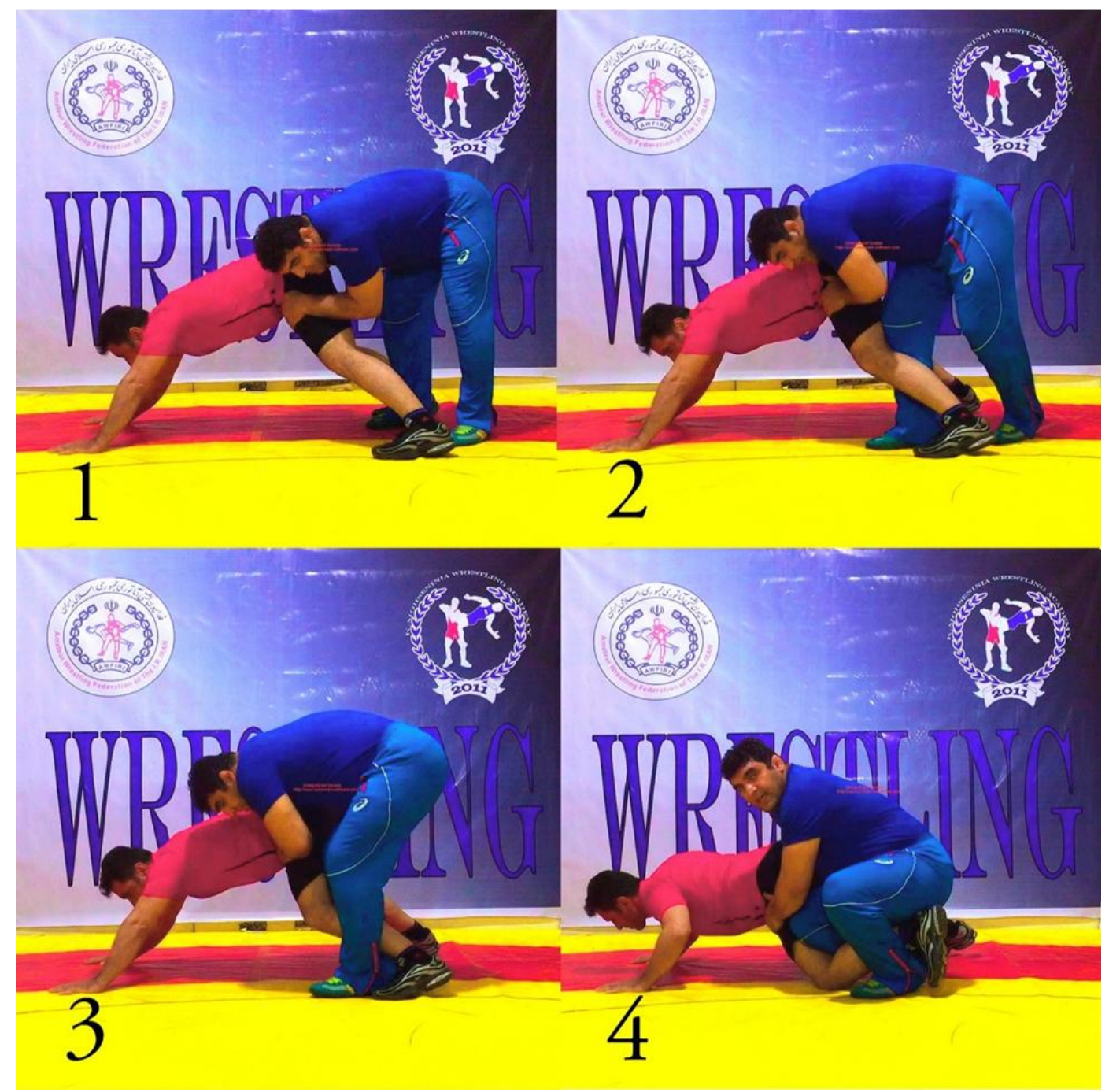

Fig. 7 Pashekan in freestyle wrestling. 


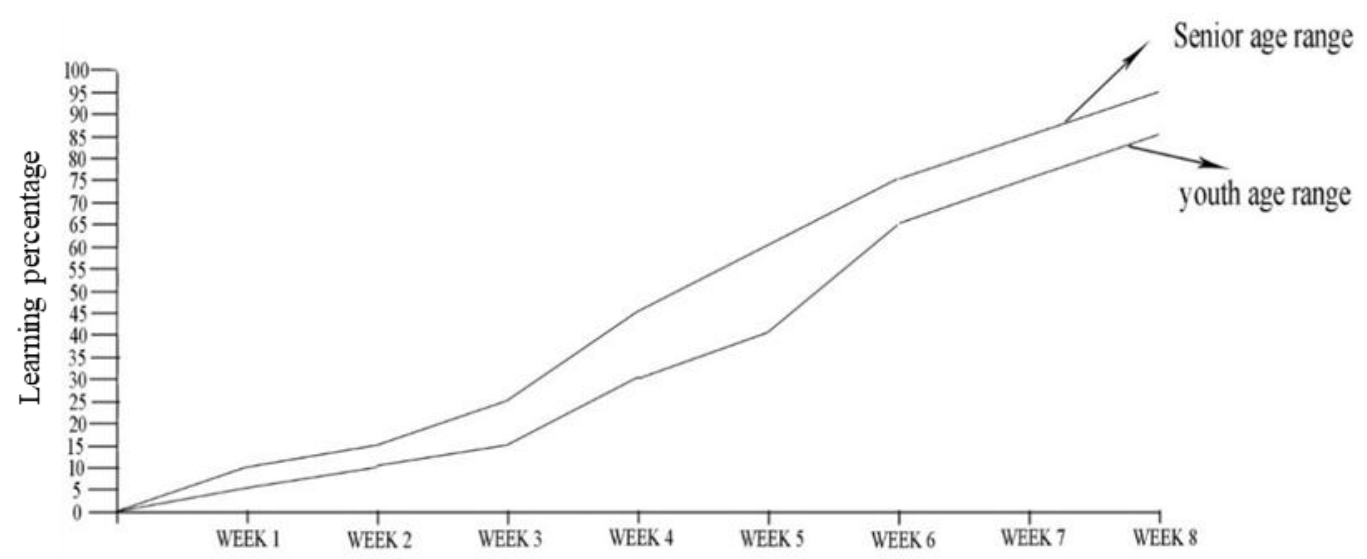

Fig. 8 Pashekan curve of learning period.

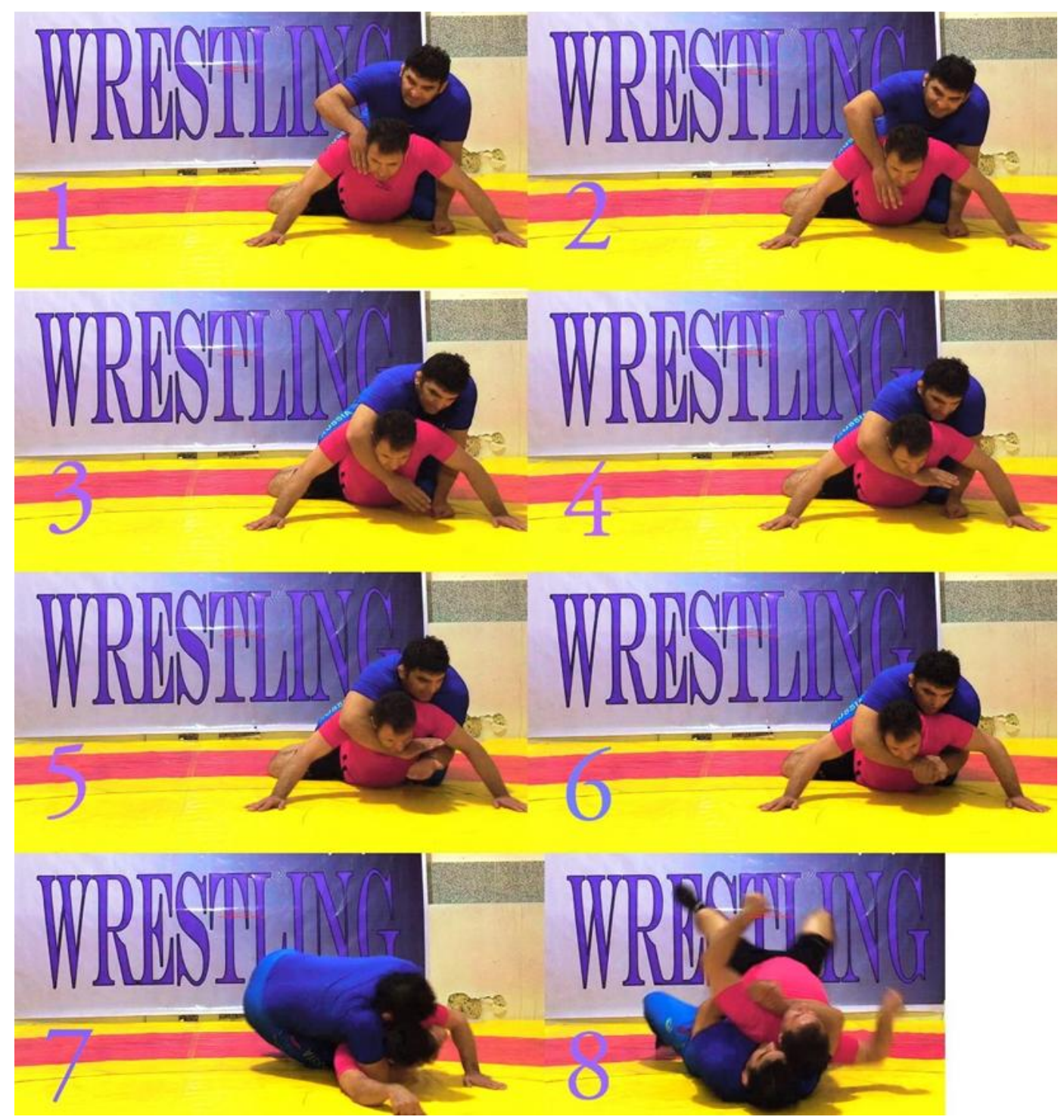

Fig. 9 Barandaze Gardanin* freestyle wrestling. 


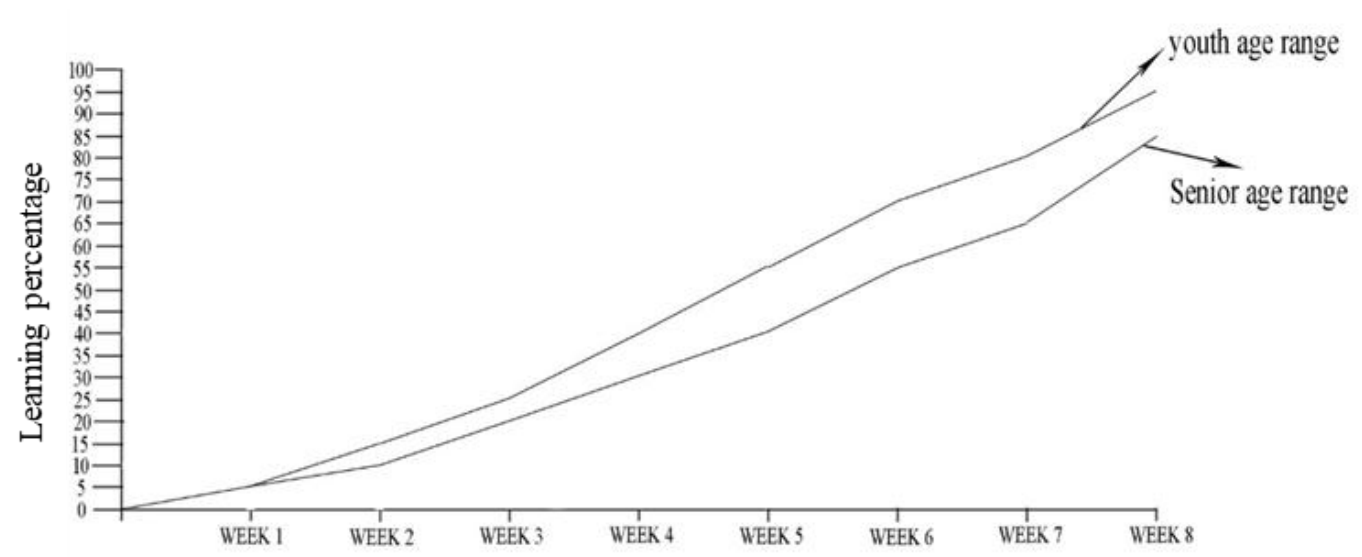

Fig. 10 Pashekan Gardanin curve of learning period.

persons who could perform it correctly in adult group reached to 15 persons. It was about 19 persons who could perform this technique correctly within last two months and only 1 person performed it for $80 \%$. About 13 persons could perform it completely in young group and within third two months. At the end of last two weeks about 17 persons performed it correctly.

Fig. 9 illustrates various steps of performing Barandaze Gardanin* Freestyle wrestling at both young and adult age levels with two credits. It is applied in sitting position and on upper part of body. As it is obvious, followings are various steps of performing this technique: (1) This technique performing in down; (2) Put the guard hand around opponent's neck; (3) Your back of the hand should be upward; (4) Pass the other hand under opponent's shoulder; (5) Catch the opponent; (6) Performing the technique.

As it is obvious in relevant diagram of Barandaze Gardan (Fig. 10), due to the little knowledge in fundamental techniques only 2 persons could perform it correctly in adult group and 3 persons in young group. There was a growing process within second two weeks due to more progress in learning of technique. Therefore there is an increase from 2 persons to 6 ones in correct performance of this technique in adult group. There was a positive slope within third two weeks, which is correspond to the 11 persons in young group. It was 14 persons in young group. It was about 17 persons in adult group within last two weeks. Only 3 persons in remained persons could perform it correctly up to $50 \%$. Only 1 person in young group could not perform it correctly.

\section{Conclusions}

Since all new innovative techniques are performing within a short term in accordance with suitable physical readiness and mental exercises and also one of the effective factors in victory of sport matches is having suitable action \& reaction, as a result experienced wrestlers could benefit from effective wrestling techniques after professional learning and performing mental exercises and good intelligence and completely in compliance with new rules of wrestling.

\section{References}

[1] Gayini, A., and Rajabi H. 2016. Individual Skills and Physical Fitness. Tehran: Center for Human Sciences Research and Development.

[2] Schmidt, R. 2016. Learning to Move. Tehran: Organization for the Study and Compilation of Humanities Books.

[3] Khaledan, A. 2016. Reducing Energy Consumption in Implementing Techniques. Tehran: Center of Physical education and sports science.

[4] Mack, G. 2015. Mind Gym: An Athlete's Guide to Inner Excellence. New York: Rising Star Studios.

[5] Russell, D. 2016. Finish Strong. Virginia: Rising Star Studios.

[6] Fessler, M. 2016. The Wrestler: A Life of Passion and the Pursuit of Greatness. Nevada: Banyan Press.

[7] Passaro, J. 2015. 6 Minutes Wrestling with Life: How the Greatest Sport on Earth Prepared Me for the Fight of My 
Life. Moscow: CreateSpace Independent Publishing Platform.
[8] Briggs, M. 1973. Greco-Roman wrestling. Athens: Athletic Press. 